\title{
Flutuações sazonais na abundância de Phalacrocorax brasilianus (Gmelin) no estuário do Saco da Fazenda, Itajaí, Santa Catarina, Brasil
}

\author{
Joaquim Olinto Branco ${ }^{1}$
}

\begin{abstract}
Seasonal changes in the abundance of Phalacrocorax brasilianus (Gmelin) in the estuary of Saco da Fazenda, Itajaí, Santa Catarina, Brazil. The Neotropic cormorant is one of the most common estuarine birds along Santa Catarina's shore, especially in artisanal fishery areas, where it obtains food easily. During the period from January, 1996 to December, 1999, and of January to December, 2001, the cormorants were monitored monthly in the estuary. The population $P$. brasilianus (Gmelin, 1789) presented seasonal changes with the same annual pattern of increment of the abundance. Significant differences were recorded between the seasons and the medium abundance of birds. Those differences can be attributed to the events of the life cycle of the species and the oscillations in the estuary water temperature.

KEY WORDS. Phalacrocorax brasilianus, seasonal changes, Neotropic cormorant
\end{abstract}

O biguá Phalacrocorax brasilianus (Gmelin, 1789) (= Phalacrocorax olivaceus) é uma ave de cor preta em plumagem adulta e marrom-escura em juvenil; sua distribuição geográfica extende-se do sudeste do Arizona (EUA) à Terra do Fogo, extremidade austral da América do Sul (A.O.U 1998), sendo freqüentemente encontrado em bandos nos lagos, grandes rios e estuários (SICK 1997). Atinge até $75 \mathrm{~cm}$ de comprimento e peso em torno de 1,3kg; possui pescoço longo, cabeça pequena, bico cinzento longo e fino, sendo que a ponta da maxila termina em forma de gancho; seus ninhos são construídos sobre árvores, em áreas alagadas ou nas proximidades de ambientes aquáticos (SICK 1997; ROSÁRIO 1996). Apesar de ser uma espécie comum nos levantamentos de ornitólogos brasileiros, existem poucas informações disponíveis sobre sua biologia e abundância no país.

Baseado na carência de informações sobre a abundância de Phalacrocorax brasilianus nas regiões sudeste-sul, esse trabalho tem como objetivo contribuir para o conhecimento das flutuações sazonais no estuário do Saco da Fazenda, Itajaí, Santa Catarina.

\section{MATERIAL E MÉTODOS}

O estuário do Saco da Fazenda está localizado entre as coordenadas

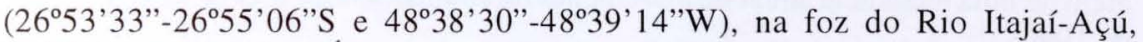
Itajaí, Santa Catarina. É um corpo d'água semi-fechado com uma área de aproximadamente $0,7 \mathrm{~km}^{2}$, resultante da ação antrópica que modificou a desembocadura original do rio com a construção dos molhes de contenção. Apresenta

1) Centro de Ciências Tecnológicas da Terra e do Mar, Universidade do Vale do Itajaí. Caixa Postal 360, 88301-970 Itajaí, Santa Catarina, Brasil. E-mail: branco@cttmar.univali.br 
substrato síltico-argiloso, profundidade máxima de 2,0 $\mathrm{m}$ (exceto nos canais de ligação com o rio, nos quais atinge até $9,0 \mathrm{~m}$ ) e amplitude de maré inferior a 1,4 $\mathrm{m}$. O estuário recebe aporte de água doce e efluentes domésticos do Ribeirão Schineider e bairro Saco da Fazenda (BRANCO 2000).

Os biguás observados pousados sobre os molhes e/ou na água do estuário, foram monitorados mensalmente, durante o período de janeiro/1996 a dezem$\mathrm{bro} / 1999$, e de janeiro a dezembro/2001.

A cada mês, foram realizados três censos, em um mesmo dia na população de biguás do Saco da Fazenda: sendo o I entre 8:00-9:00 h, o II entre 11:00-12:00 h e o III entre 15:00-6:00 h. O número médio de aves por mês, foi adotado como uma medida padrão da abundância mensal.

Utilizou-se um barco a remo para o deslocamento na área de estudo, o que permitiu uma boa aproximação das aves, facilitando o registro do número de biguás através de observação direta com binóculos 10 × 50 aumento.

O teste ANOVA (SOKAL \& ROHLF 1969) foi utilizado para verificar a existência de diferenças significativas na abundância dos exemplares entre os anos de amostragens e nas estações do ano. O contraste das médias através do teste Tukey-Kramer, quando da ocorrência de diferenças significativas, foi aplicado para indicar a fonte causadora das variações. Determinou-se a correlação entre a abundância média de biguás em 2001, com a biomassa de peixes capturados nas pescarias experimentais do estuário do Saco da Fazenda, temperatura e salinidade da água de superfície, através da análise de correlação de Spearman (SIEGEL 1956).

\section{RESULTADOS}

A análise da figura 1, mostra que a população de $P$. brasilianus no estuário do Saco da Fazenda, apresentou ao longo do período de estudo um padrão uniforme de flutuação da abundância. Com redução gradativa a partir do mês de janeiro até atingir as menores abundâncias médias entre abril-junho, seguido de incremento moderado e de pequenas oscilações, alcançando as maiores abundâncias entre outubro-dezembro. Embora, não tenham ocorrido diferenças significativas ( $\mathrm{F}_{4-55}=$ $1,477, \mathrm{p}=0,05$ ) entre a abundância média mensal de biguás e os cinco anos de censos, a população apresentou variações acentuadas ao longo do ano, sendo que as menores abundâncias foram registradas em maio/1998 (6,7 exemplares) e as maiores em dezembro/2001 (597,5) (Fig. 1).

Os cinco anos de censo, quando reunidos em uma série temporal (Fig. 2), evidenciam que ocorrem flutuações sazonais bem definidas na abundância de $P$. brasilianus ao longo dos anos. Essas flutuações indicaram sempre o mesmo padrão, além de uma tendência anual de incremento na abundância de biguás a partir do ano de 1996.

A figura 3, ressalta essas flutuações indicando diferenças significativas $\left(F_{3}-56=19,234 ; p=0,001\right)$ entre as estações do ano e a abundância de biguás. O contraste das médias, demonstrou que essas diferenças ocorreram, principalmente, na primavera, onde foram registradas as maiores abundâncias sazonais $(683,8 \pm$ $243,6)$ e verão $(464,3 \pm 240,6)$, enquanto que as menores, foram registradas entre os meses de outono $(138,0 \pm 169,6)$ e inverno $(302,4 \pm 152,1)$. 

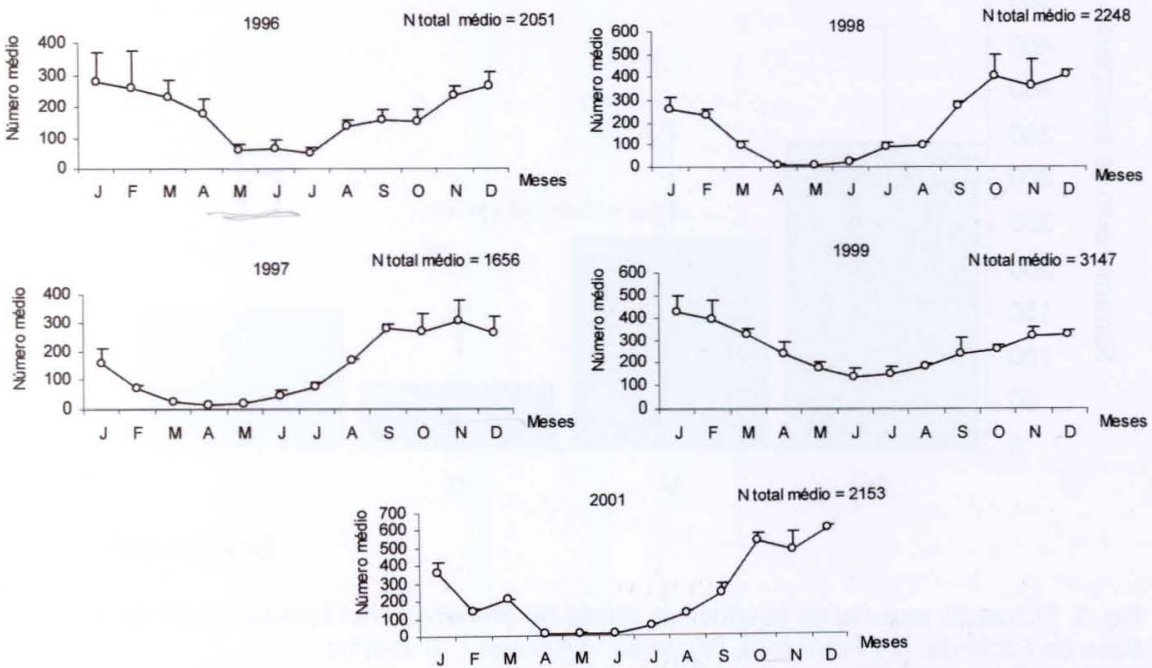

Fig. 1. Abundância média mensal de Phalacrocorax brasilianus, durante o período de 1996 a 1999 e 2001.

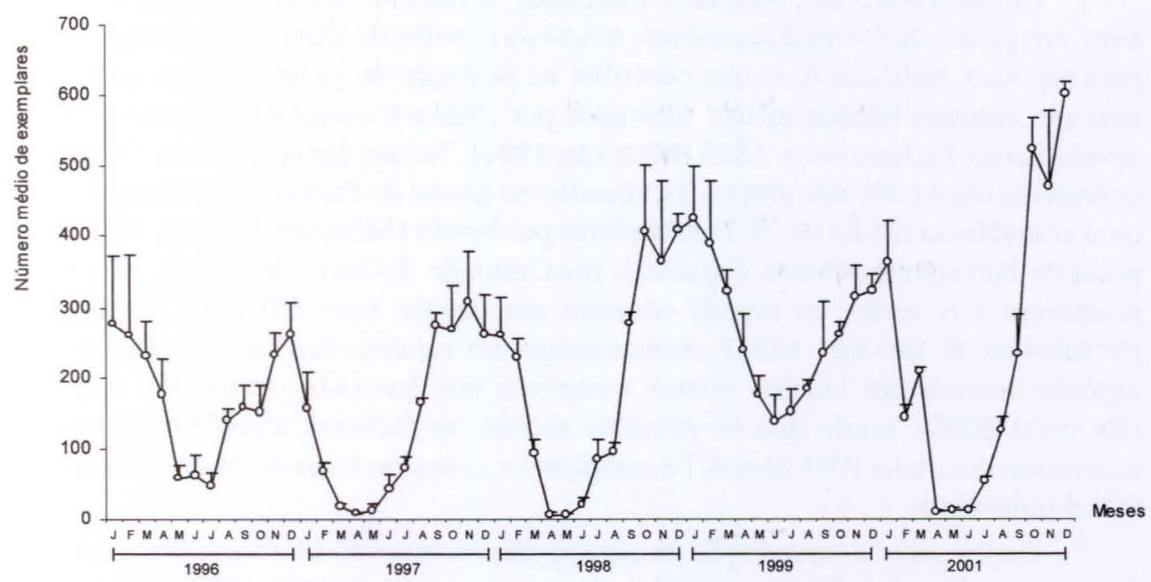

Fig. 2. Flutuação temporal da abundância média mensal de Phalacrocorax brasilianus, no estuário do Saco da Fazenda, ao longo do período de estudo.

A análise de correlação de Spearman, indicou a existência de relação positiva $(\mathrm{r}=0,616, \mathrm{n}=12, \mathrm{p}<0,05)$ e muito significativa entre a abundância de biguás e a temperatura da água de superfície, e correlação inversa $(r=-0,209, n=12, p=0,05)$ não significativa entre abundância de biguás e a biomassa de peixes capturados nas pescarias experimentais no estuário do Saco da Fazenda; bem como nenhuma correlação $(r=-0,059, n=12, p=0,05)$ entre os teores de salinidade da água de superfície e abundância de biguás. 


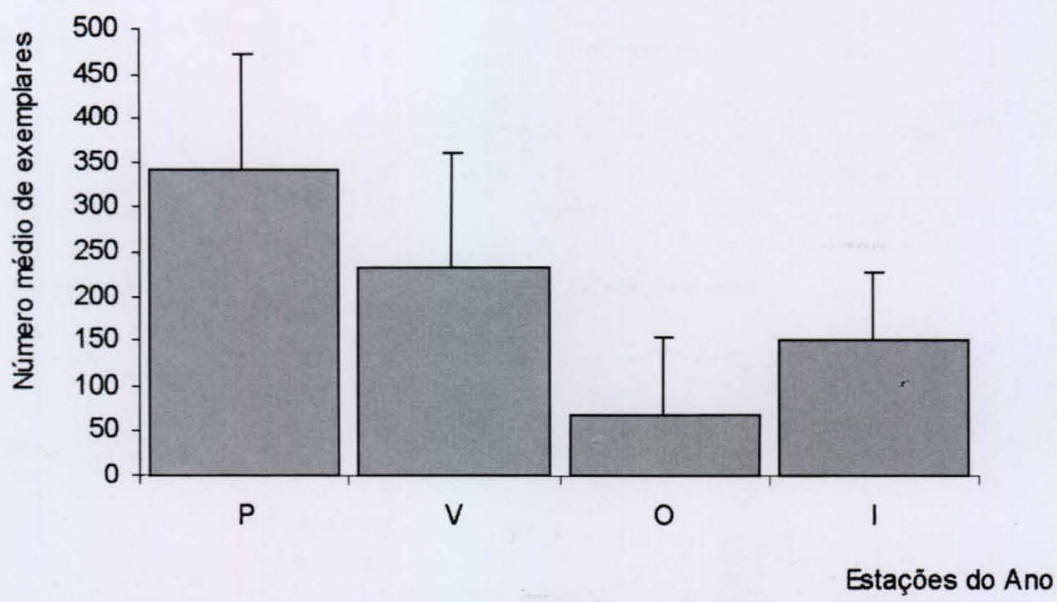

Fig. 3. Flutuação sazonal da abundância média de Phalacrocorax brasilianus, no estuário do Saco da Fazenda. (P) Primavera, (V) verão, (O) outono, (I) inverno.

\section{DISCUSSÃO}

Em ambiente de influência marítima, agrupamentos heteroespecíficos de aves, em geral, são formados em decorrência da partilha de alimento, local adequado para repouso, nidificação, o que contribui na proteção do grupo. Nesses ecossistemas são comuns bandos mistos formados por Phalacrocorax brasilianus e Larus dominicanus Lichtenstein, 1823 (MORAES 1991). Nestes agrupamentos, os biguás ocorreram em 41,6\% dos grupos localizados no litoral do Paraná, contribuindo com uma abundância média de 39,1 exemplares por bando (MORAES \& KRUL 1995). Na praia de Navegantes (Santa Catarina), proximidade do local de estudo, durante a primavera e o verão, os biguás ocorrem em bandos com 6,0 a 10 exemplares (SCHIEFLER \& SOARES 1994); enquanto que no estuário do Saco da Fazenda, a espécie ocorreu em bandos mistos composto por gaivotão, trinta-réis e garças (BRANCO 2000), sendo que no presente estudo, as menores abundâncias médias ocorreram em maio/1998 com 6,7 exemplares e as maiores em dezembro/2001 com 597,5 indivíduos.

Dados sobre a reprodução da espécie são escassos na literatura especializada do país, sendo que informes esporádicos como os de AzEVEDo (1995), dão conta da presença de pequenas colônias reproduzindo no litoral catarinense. SICK (1997) registrou que após a nidificação, os biguás emigram em grandes bandos para locais como a Lagoa dos Patos (Rio Grande do Sul). Agrupamentos com um número elevado de exemplares são comuns no estuário Saco da Fazenda a partir de agosto até fevereiro (BRANCO 2000).

Embora não tenha ocorrido correlação significativa entre a biomassa de peixes capturados nas pescarias experimentais do estuário e a abundância de biguás, segundo BRANCO (2001), uma parcela significativa da ictiofauna capturada na pesca artesanal do camarão sete-barbas é descartada no mar e utilizada como fonte de alimento por $P$. brasilianus, principalmente durante os meses de primavera e verão. 
Essa modalidade de pesca é praticada com maior intensidade no início da manhã estendendo-se até as primeiras horas da tarde, nas proximidades do estuário (BRANCO et al. 1999). Dessa forma, flutuações sazonais na abundância de biguás, também podem estar associadas à produtividade pesqueira da região costeira. Essa interação entre as aves e barcos de pesca é evidente no início da manhã, onde ocorrem as maiores abundâncias; com a redução do número de embarcações pescando, os biguás retornam gradativamente ao estuário.

De acordo com YORIO et al. (1994), ocorrem variações estacionais relativamente altas na abundância de $P$. brasilianus na colônia reprodutiva de Punta Leon, Argentina. Padrões semelhantes de flutuações foram registrados na população de biguás do estuário Saco da Fazenda, estas podem ser associadas aos eventos do ciclo reprodutivo da espécie ou influenciadas por outros fatores, como a queda de temperatura da água de superfície, durante as estações de outono e inverno.

O estuário do Saco da Fazenda, apesar do impacto causado pelo afluxo de efluentes domésticos e resíduos sólidos, atua como área de descanso, manutenção da plumagem e proteção para aves aquáticas (BRANCO 2000). Nessa área é freqüente a ocorrência de biguás em atividade de pesca, onde capturam juvenis de tainha, bagres, manjubas e siris. O consumo de pequenos peixes por $P$. brasilianus, pode ser atribuído à economia de energia gasta na captura, visto que os biguás são mais eficientes em predar os juvenis nas margens dos lagos com vegetação, que os adultos das áreas abertas (MORRISON et al. 1978).

As flutuações sazonais no número de exemplares em agrupamentos mono ou heteroespecíficos de aves reforçam a necessidade de considerar a época do ano, horário e o número de censos para determinar adequadamente o tamanho das populações. O monitoramento desses agrupamentos nos próximos anos, poderá contribuir na compreensão das interações entre as espécies e na avaliação da importância das populações do estuário, no contexto regional.

\section{REFERÊNCIAS BIBLIOGRÁFICAS}

A.O.U. (American Ornithologists Union). 1998. Check-list of north American birds. Lawrence, American Ornithologists Union. $17^{\text {th }}$ ed., 829 p.

Azevedo, T.R. 1995. Estudo da avifauna do campus da Universidade Federal de Santa Catarina (Florianópolis). Biotemas, Florianópolis, 8 (2): 7-35.

Branco, J.O.; M.J. Lunardon-Branco; F.X. Souto \& C.R. Guerra. 1999. Estrutura populacional do camarão sete-barbas Xiphopenaeus kroyeri (Heller, 1862), na foz do Rio Itajaí-Açú, SC, Brasil. Braz. arch. biol. technol., Curitiba, 42 (1): 115-126.

Branco, J.O. 2000. Avifauna associada ao estuário do Saco da Fazenda. Revta bras. Zool., Curitiba, 17 (2): 387-394.

2001. Descartes da pesca do camarão sete-barbas como fonte de alimento para aves marinhas.

Revta Bras. Zool., Curitiba, 18 (1): 293-300.

Moraes, V.S. 1991. Avifauna da Ilha do Mel, litoral do Paraná. Arq. Biol. Tecnol., Curitiba, 34 (2): 195-205.

Moraes, V.S. \& R. Krul. 1995. Aves associadas a ecossistemas de influência marítima no litoral do Paraná. Arq. Biol. Tecnol., Curitiba, 38 (1): 121-134.

Morrison, M.L.; R.D. Slack \& E. Shanley JR. 1978. Age and foraging ability relationships of olivaceous cormorants. Wilson Bull. 90 (3): 414-422. 
RosÁRIO, L.A. 1996. As aves em Santa Catarina: distribuição geográfica e meio ambiente. Florianópolis, FATMA, 326p.

SCHIEFLER, A.F. \& M. SoAres. 1994. Estudo comparativo da avifauna das praias de Navegantes e Laguna, Santa Catarina. Biotemas, Florianópolis, 7 (1, 2): 31-45.

Sick, H. 1997. Ornitologia Brasileira. Rio de Janeiro, Ed. Nova Fronteira, 912p.

SIEGEL, S. 1956. Nonparametric statistic for the behavioral sciences. New York, McGraw-Hill, 312p. SOKAL, R.R. \& F.J. ROHLF. 1969. Biometry, the principles and practies of statistics in biological research. San Francisco, W.H. Freeman, 776p.

Yorio, P.; F. Quintana; C. CAMPagna \& G. Harris. 1994. Diversidad, abundancia y dinamica espacio-temporal de la colonia mixta de aves marinas em Punta Leon, Patagonia. Ornit. Neotrop. 5 (2): 69-77.

Recebido em 20.V.2002; aceito em 13.IX.2002. 